\title{
Frequency-Stable Ionic-Type Hybrid Gate Dielectrics for High Mobility Solution-Processed Metal-Oxide Thin-Film Transistors
}

\author{
Jae Sang Heo ${ }^{1}$, Seungbeom Choi ${ }^{2}$, Jeong-Wan Jo ${ }^{1}$, Jingu Kang ${ }^{1}$, Ho-Hyun Park ${ }^{1}$, \\ Yong-Hoon Kim ${ }^{2, *}$ and Sung Kyu Park ${ }^{1, *}$ \\ 1 School of Electrical and Electronic Engineering, Chung-Ang University, Seoul 06980, Korea; \\ heojs38@gmail.com (J.S.H.); jzw0108@nate.com (J.-W.J.); uangelion@gmail.com (J.K.); \\ hohyun@cau.ac.kr (H.-H.P.) \\ 2 SKKU Advanced Institute of Nanotechnology (SAINT) and School of Advanced Materials Science and \\ Engineering, Sungkyunkwan University, Suwon 16419, Korea; oyenice@skku.edu \\ * Correspondence: yhkim76@skku.edu (Y.-H.K.); skpark@cau.ac.kr (S.K.P.)
}

Academic Editor: Pedro Barquinha

Received: 19 April 2017; Accepted: 1 June 2017; Published: 3 June 2017

\begin{abstract}
In this paper, we demonstrate high mobility solution-processed metal-oxide thin-film transistors (TFTs) by using a high-frequency-stable ionic-type hybrid gate dielectric (HGD). The HGD gate dielectric, a blend of sol-gel aluminum oxide $\left(\mathrm{AlO}_{x}\right)$ and poly(4-vinylphenol) (PVP), exhibited high dielectric constant $(\varepsilon \sim 8.15)$ and high-frequency-stable characteristics $(1 \mathrm{MHz})$. Using the ionic-type HGD as a gate dielectric layer, an minimal electron-double-layer (EDL) can be formed at the gate dielectric/ $/ \mathrm{InO}_{x}$ interface, enhancing the field-effect mobility of the TFTs. Particularly, using the ionic-type $\mathrm{HGD}$ gate dielectrics annealed at $350{ }^{\circ} \mathrm{C}, \mathrm{InO}_{x}$ TFTs having an average field-effect mobility of $16.1 \mathrm{~cm}^{2} / \mathrm{Vs}$ were achieved (maximum mobility of $24 \mathrm{~cm}^{2} / \mathrm{Vs}$ ). Furthermore, the ionic-type HGD gate dielectrics can be processed at a low temperature of $150{ }^{\circ} \mathrm{C}$, which may enable their applications in low-thermal-budget plastic and elastomeric substrates. In addition, we systematically studied the operational stability of the $\mathrm{InO}_{x}$ TFTs using the HGD gate dielectric, and it was observed that the HGD gate dielectric effectively suppressed the negative threshold voltage shift during the negative-illumination-bias stress possibly owing to the recombination of hole carriers injected in the gate dielectric with the negatively charged ionic species in the HGD gate dielectric.
\end{abstract}

Keywords: metal-oxide semiconductors; thin-film transistors; hybrid gate dielectric; low temperature solution-process; high mobility

\section{Introduction}

Solution-processed metal-oxide thin-film transistors (TFTs) are emerging as a potential replacement for amorphous and low-temperature polycrystalline silicon TFTs in active-matrix electronics including displays, sensor arrays, and driving circuits due to their relatively high carrier mobility and good scalability over a large area [1-4]. In addition, their amorphous nature and high optical transparency in the visible range may open up a new promising application for transparent and wearable electronics. In general, the metal-oxide TFTs such as indium-gallium-zinc oxide exhibit a higher carrier mobility than that of the amorphous silicon and organic TFTs $[5,6]$. However, in order to realize high definition, high frame-rate displays, and the relevant driving circuitry, the carrier mobility must be further improved while exhibiting good operational stability. For these reasons, various metal-oxide semiconductors [7,8], gate dielectrics [9,10], novel device structures [11,12], and post treatments $[13,14]$ have been proposed to enhance the carrier mobility of these devices. Among the 
various approaches in achieving high mobility metal-oxide TFTs, using an ionic-type gate dielectric is a promising method of achieving both the high mobility and low voltage operation characteristics [15-19]. Previously, ion-gel-type gate dielectrics [20], protonated $\mathrm{SiO}_{2}$ gate dielectrics [21], and electrolyte gate dielectrics have been explored. Although these ionic-type gate dielectrics showed promising results for achieving high mobility devices, their limited operation at high frequencies may hinder their practical application in active-matrix electronics. In this respect, new types of ionic-type gate dielectrics, which are capable of operating at high frequencies, are now in high demand. Moreover, for the consistency in the fabrication process of oxide TFTs, solution processing of frequency-stable ionic-type gate dielectrics will be more favorable.

Here, we demonstrate solution-processed ionic-type gate dielectrics based on $\mathrm{AlO}_{x}$ and a hybrid of $\mathrm{AlO}_{x}$ and poly(4-vinylphenol) (PVP) materials. In particularly, the low-temperature solution-processed hybrid gate dielectric (HGD) exhibited reasonably high capacitance and dielectric constant, and only a slight decrease in areal capacitance was observed at high frequencies up to $1 \mathrm{MHz}$ along with minimal hysteresis due to the local confinement of mobile ions inside the polymer networks and consequent suppression of electron-double-layer (EDL) effects [22]. In addition, using the solution-processed HGD gate dielectrics in indium oxide $\left(\mathrm{InO}_{x}\right) \mathrm{TFTs}$, relatively high mobilities up to $24 \mathrm{~cm}^{2} / \mathrm{Vs}$ were achieved due to the formation of an acceptable EDL at the gate dielectric/ $\mathrm{InO}_{x}$ interface for high frequency applications. These results demonstrate that the low-temperature solution-processed HGD gate dielectrics may enable the high-mobility, low-voltage, and high-frequency operation of oxide TFTs.

\section{Experimental Procedure}

For the fabrication of an $\mathrm{AlO}_{x}$ gate dielectric, an $\mathrm{AlO}_{x}$ precursor solution was prepared by dissolving $0.8 \mathrm{M}$ aluminum nitrate nonahydrate in 2-methoxyethanol (2-ME) followed by vigorously stirring at $75^{\circ} \mathrm{C}$ for $12 \mathrm{~h}$. For the HGD gate dielectric, a poly(4-vinylphenol) (PVP) precursor was dissolved by stirring in 2-ME for $12 \mathrm{~h}$ to form a $5 \mathrm{mg} \mathrm{mL}^{-1}$ solution. Then, an additional 5\% PVP $\left(\mathrm{AlO}_{x}: 5 \% \mathrm{PVP}\right)$ was added to the $\mathrm{AlO}_{x}$ precursor solution and stirred for $6 \mathrm{~h}$ at $75^{\circ} \mathrm{C}$. For the $\mathrm{InO}_{x}$ channel formation by a solution process, $0.1 \mathrm{M}$ indium nitrate was dissolved in 2-ME and stirred for 12 $\mathrm{h}$ at $75^{\circ} \mathrm{C}$. For the electrical characterization of solution-processed gate dielectrics, a heavily-doped $\mathrm{n}^{+}$ $\mathrm{Si}$ wafer was used as a substrate, and $\mathrm{Si}$ wafer $/ \mathrm{AlO}_{x}$ (or HGD)/ Al (metal-insulator-metal; MIM) and Si wafer $/ \mathrm{AlO}_{x}$ (or HGD)/ $\mathrm{InO}_{x} / \mathrm{Al}$ (metal-insulator-semiconductor; MIS) structures were constructed. The top Al was deposited by using a thermal evaporator with a shadow mask (effective area: $100 \times 100 \mu \mathrm{m}^{2}$ ). For the fabrication of $\mathrm{InO}_{x}$ TFTs, a borosilicate glass was used as a substrate. Then, $\mathrm{Cr}$ gate electrode was deposited by e-beam evaporation and patterned by using standard photolithography and wet etching processes. Afterwards, the $\mathrm{AlO}_{x}$ or $\mathrm{HGD}$ precursor solution was spin-coated over the gate electrode to form a gate dielectric layer. Thermal annealing treatment at $150,250,350$, and $450{ }^{\circ} \mathrm{C}$ for $30 \mathrm{~min}$ was carried out in an ambient air condition, resulting in thicknesses of 89,60, 50 and $40 \mathrm{~nm}$, respectively. After the formation of the gate dielectric, an $\mathrm{InO}_{x}$ precursor solution was spin-coated to form a channel layer and thermally annealed at $250{ }^{\circ} \mathrm{C}$ for $30 \mathrm{~min}$, resulting in a thickness of $7 \mathrm{~nm}$. For the source/drain electrodes, 60-nm-thick indium zinc oxide (IZO) was deposited by sputtering and patterned by a lift-off process (Figure 1a). The channel width and length of the $\mathrm{InO}_{x} \mathrm{TFTs}_{\text {were }}$ $100 \mu \mathrm{m}$ and $10 \mu \mathrm{m}$, respectively. The thickness of the gate dielectric layer was measured by using spectroscopic ellipsometry, and to obtain the dielectric constant $\left(\varepsilon_{r}\right)$ of the film, the capacitance value (C) was first assessed by using a precision LCR meter and the dielectric constant was extracted using the following equation:

$$
C=\varepsilon_{0} \varepsilon_{r} \frac{A}{d}
$$

where $C$ is the capacitance, $A$ is the overlapped area between top and bottom electrodes, $d$ is the thickness of gate dielectric layer, and $\varepsilon_{0}$ is the vacuum permittivity, respectively.

To evaluate the dielectric properties of $\mathrm{AlO}_{x}$ and $\mathrm{HGD}$ films, areal capacitance vs. frequency and leakage current density vs. electric field were analyzed using a precision LCR meter and 
a semiconductor parameter analyzer, respectively. In addition, the electrical characterization and bias stability tests for the $\mathrm{InO}_{x}$ TFTs were carried out using a semiconductor parameter analyzer under an ambient air condition with a relative humidity of $\sim 33 \%$ and a temperature of $24{ }^{\circ} \mathrm{C}$. For analyzing the transfer characteristics, the gate voltage was swept from -5 to $6 \mathrm{~V}$ with a voltage step of $0.1 \mathrm{~V}$. Additionally, it should be noted that, since the degree of hysteresis in the transfer curves and the field-effect mobility of $\mathrm{InO}_{x}$ TFTs with low-temperature annealed gate dielectric can vary with the gate-voltage sweep rate, we applied a gate-voltage sweep rate of $0.13 \mathrm{~V} / \mathrm{s}$ for all TFT measurement.

(a)

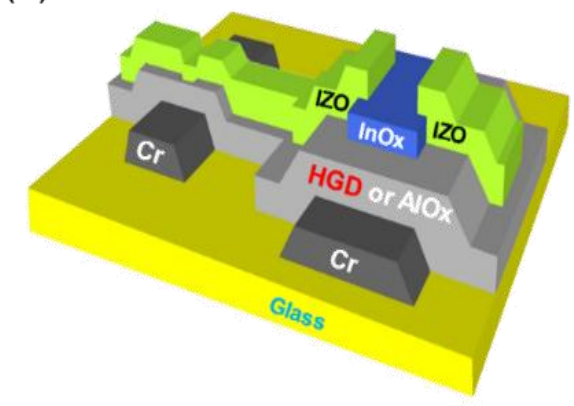

(b)

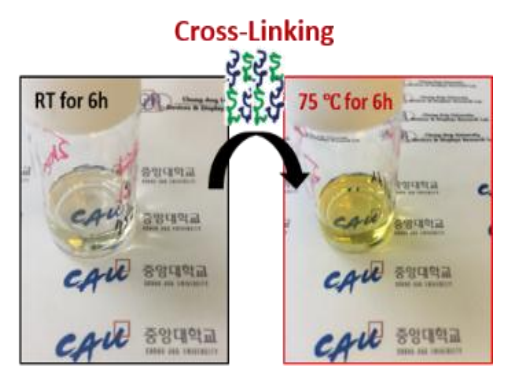

Figure 1. (a) Schematic illustration of $\mathrm{InO}_{x}$ TFTs using $\mathrm{AlO}_{x}$ or $\mathrm{HGD}$ gate dielectric layer; (b) Photographs of an HGD solution before and after a thermal cross-linking.

\section{Results and Discussion}

In order to examine the dielectric properties of solution-processed $\mathrm{AlO}_{x}$ and $\mathrm{HGD}$ layers, the areal capacitance vs. frequency (C-F) and the current density vs. electric field (J-E) characteristics were measured. In addition, the difference in the surface morphology of $\mathrm{AlO}_{x}$ and HGD films is negligible. Figure $2 \mathrm{a}, \mathrm{b}$ show the areal capacitance vs. frequency data for $\mathrm{AlO}_{x}$ and $\mathrm{HGD}$ gate dielectrics, respectively. In the case of the $\mathrm{AlO}_{x}$ gate dielectric, the capacitance value and the corresponding dielectric constant showed an increasing trend with the annealing temperature. Particularly, with an annealing temperature of $150{ }^{\circ} \mathrm{C}$, the dielectric constant was 7.09 (thickness of $89 \mathrm{~nm}$ ), but it decreased to 6.11 and 5.11 when the annealing temperature was increased to $350{ }^{\circ} \mathrm{C}$ and $450{ }^{\circ} \mathrm{C}$, respectively. In the case of HGD gate dielectric, a similar behavior was observed as shown in Figure $2 \mathrm{~b}$. With an annealing temperature of $150{ }^{\circ} \mathrm{C}, \mathrm{HGD}$ gate dielectric exhibited a dielectric constant of 8.15 , and decreased to 6.10 and 6.01 when the annealing temperature was increased to $350{ }^{\circ} \mathrm{C}$ and $450{ }^{\circ} \mathrm{C}$, respectively. It should be noted that the areal capacitance value and the corresponding dielectric constant were higher in the HGD gate dielectric, which can be attributed to the mobile ions in the polymer network combined with $\mathrm{AlO}_{x}$ film. To further investigate the insulating properties, the current density vs. electric field measurements for $\mathrm{AlO}_{x}$ and HGD gate dielectrics were carried out. Figure 2c, d show the current density vs. electric field data for $\mathrm{AlO}_{x}$ and $\mathrm{HGD}$ gate dielectrics, respectively. In the case of $\mathrm{AlO}_{x}$ gate dielectric, even a low temperature annealing of $150{ }^{\circ} \mathrm{C}$ resulted in reasonable insulating properties. With the annealing temperature of $150{ }^{\circ} \mathrm{C}$, the leakage current density was $4.45 \times 10^{-6} \mathrm{~A} / \mathrm{cm}^{2}$ at an electric field of $2 \mathrm{MV} / \mathrm{cm}$. Further increasing the annealing temperature to $350{ }^{\circ} \mathrm{C}$ and $450{ }^{\circ} \mathrm{C}$ improved the insulating properties, and the current density was decreased to $4.44 \times 10^{-7} \mathrm{~A} / \mathrm{cm}^{2}$ and $8.29 \times 10^{-10} \mathrm{~A} / \mathrm{cm}^{2}$, respectively. In the case of HGD gate dielectric, even a low temperature annealing of $150{ }^{\circ} \mathrm{C}$ resulted in reasonable insulating properties. At an annealing temperature of $150^{\circ} \mathrm{C}$, the leakage current density was $1.47 \times 10^{-5} \mathrm{~A} / \mathrm{cm}^{2}$ at an electric field of $2 \mathrm{MV} / \mathrm{cm}$. Increasing the annealing temperature to $350{ }^{\circ} \mathrm{C}$ and $450{ }^{\circ} \mathrm{C}$ improved the insulating properties and the current density was decreased to $1.47 \times 10^{-6} \mathrm{~A} / \mathrm{cm}^{2}$ and $2.37 \times 10^{-9} \mathrm{~A} / \mathrm{cm}^{2}$, respectively. Additionally, an $\mathrm{AlO}_{x}$ and $\mathrm{HGD}$ film with the annealing temperature of $250{ }^{\circ} \mathrm{C}$ have insulator properties similar to those of $150{ }^{\circ} \mathrm{C}$-annealed gate dielectric films, while thickness were decreased from 89 to $60 \mathrm{~nm}$. The slightly high leakage current density observed in HGD gate dielectrics provides that a profound 
number of mobile ions may exist in the gate dielectric layer. However, even with the mobile ions, the leakage current density is reasonably low to be utilized as a gate dielectric layer.

(a)

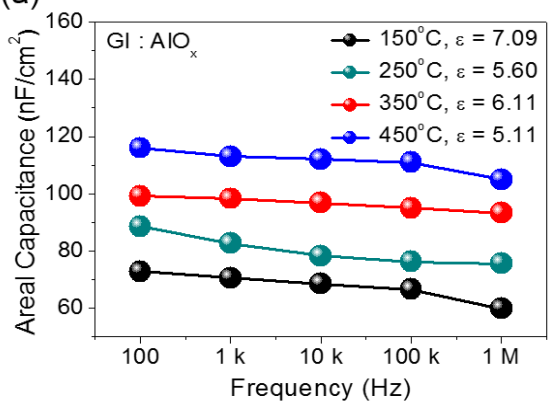

(c)

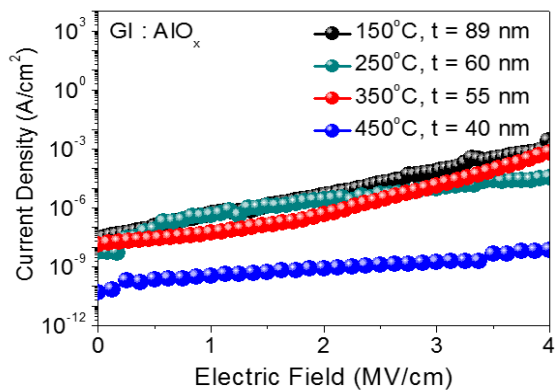

(e)

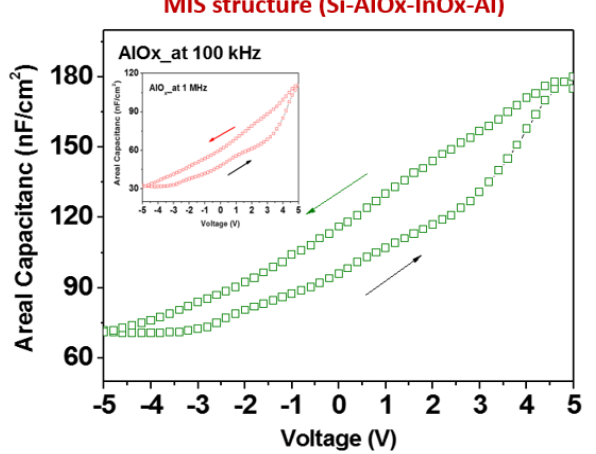

(g)

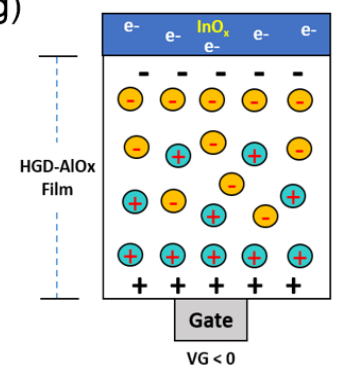

(b)

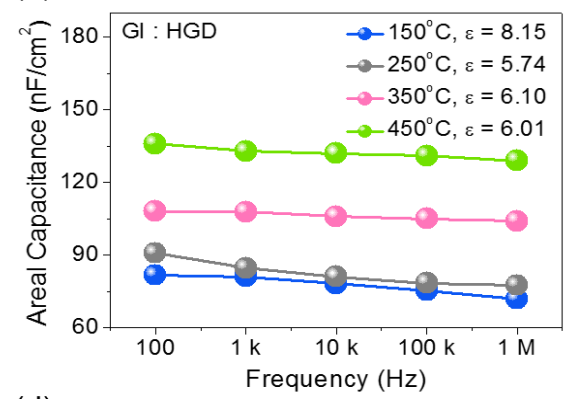

(d)

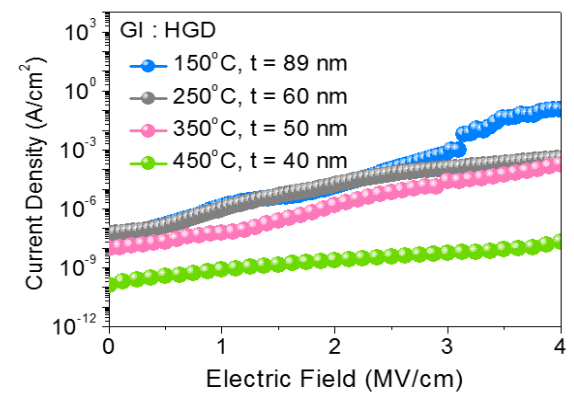

(f)
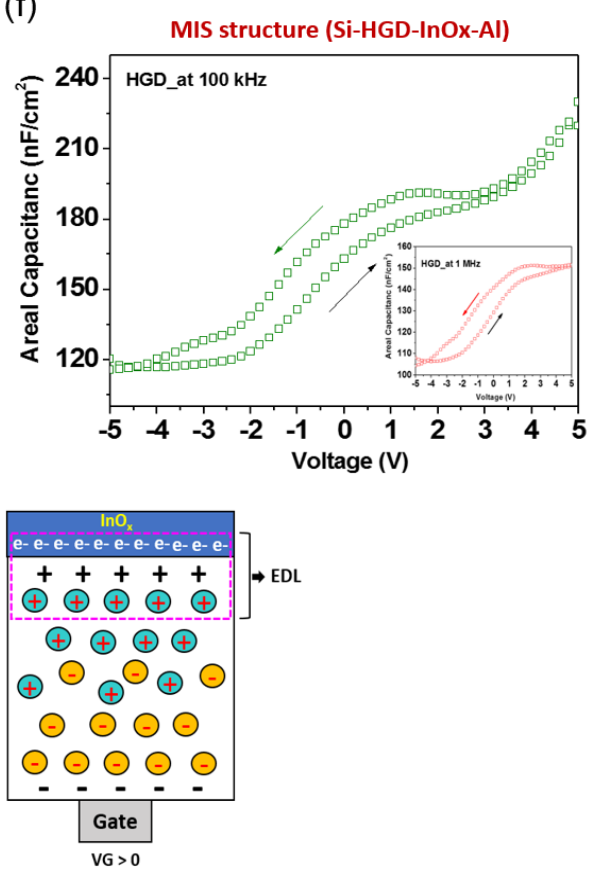

Figure 2. Electrical characteristics for solution-processed $\mathrm{AlO}_{x}$ or $\mathrm{HGD}$ dielectric layer using metal-insulator-metal structure (MIM; $\mathrm{Si} / \mathrm{AlO}_{x}$ or $\left.\mathrm{HGD} / \mathrm{Al}\right)$ with the different annealing conditions (at 150, 250, 350, and $450^{\circ} \mathrm{C}$ ). The areal capacitance per area-frequency (C-F) of solution-processed (a) $\mathrm{AlO}_{x}$ and (b) HGD dielectric layer; leakage current density-electric field (J-E) of solution-processed (c) $\mathrm{AlO}_{x}$ and (d) $\mathrm{HGD}$ dielectric layer; the C-V characteristics of an (e) $\mathrm{AlO}_{x}$ and (f) $\mathrm{HGD}_{\text {gate dielectric }}$ $\left(150{ }^{\circ} \mathrm{C}\right)$ at $100 \mathrm{kHz}$ and $1 \mathrm{MHz}$ (inset) using metal-insulator-semiconductor structure (MIS; $\mathrm{Si} / \mathrm{AlO}_{x}$ or $\mathrm{HGD} / \mathrm{InO}_{x} / \mathrm{Al}$ ); (g) the polarization mechanisms and electric double layer formation in $\mathrm{InO}_{x}$ TFTs with HGD dielectric layer. 
The presence of mobile ions in the solution-processed $\mathrm{AlO}_{x}$ and HGD gate dielectrics were further validated by measuring the areal capacitance change as a function of bias polarity. Figure $2 \mathrm{e}, \mathrm{f}$ show the areal capacitance vs. voltage (C-V) plots for $\mathrm{AlO}_{x}$ and $\mathrm{HGD}$ gate dielectrics annealed at $150{ }^{\circ} \mathrm{C}$, respectively. Here, the $\mathrm{C}-\mathrm{V}$ characteristics were obtained using an MIS structure of $\mathrm{Si}$ wafer $/ \mathrm{AlO}_{x}$ (or HGD)/ $\mathrm{InO}_{x} / \mathrm{Al}$ at frequencies of $100 \mathrm{kHz}$ and $1 \mathrm{MHz}$ (inset). As displayed, the areal capacitance increases when the bias polarity changed from negative to positive bias, which can be attributed to the formation of an $\mathrm{EDL}$ at the $\mathrm{AlO}_{x}$ (or HGD)/ $\mathrm{InO}_{x}$ interface. Particularly, in the case of $\mathrm{AlO}_{x}$ gate dielectric, the hysteresis was comparably larger than that of an HGD gate dielectric, possibly indicating a larger amount of residual mobile ions present in the film. As schematically illustrated in Figure $2 \mathrm{~g}$, when a negative bias is applied to the $\mathrm{Si}$ wafer, positively charged mobile ions accumulate near the $\mathrm{AlO}_{x}$ (or HGD)/Si wafer interface, while the negatively charged mobile ions move toward the $\mathrm{AlO}_{x}$ or $\mathrm{HGD} / \mathrm{InO}_{x}$ interface. Since the majority carrier in the $\mathrm{InO}_{x}$ semiconductor is an electron (an $\mathrm{n}$-type), the negatively charged mobile ions near the $\mathrm{AlO}_{x}$ (or HGD)/ $\mathrm{InO}_{x}$ interface repel the electrons in the $\mathrm{InO}_{x}$ channel. However, when a positive bias is applied to the Si wafer, the positively charged mobile ions move toward $\mathrm{AlO}_{x}$ (or HGD)/ $\mathrm{InO}_{x}$ interface. Then, these positively charged mobile ions accumulate electrons in the $\mathrm{InO}_{x}$ channel, forming an $\mathrm{EDL}$ at the $\mathrm{AlO}_{x}$ (or $\mathrm{HGD}$ )/ $\mathrm{InO}_{x}$ interface. This in turn increases the areal capacitance of the device. The different capacitance with applied bias frequency may constitute solid evidence of the formation of an EDL layer. The lower capacitance with larger hysteresis at high frequency $(1 \mathrm{MHz})$ is likely due to the less responsive mobile ions inside the $\mathrm{AlO}_{x}$ films.

Using the solution-processed $\mathrm{AlO}_{x}$ and $\mathrm{HGD}$ layers as a gate dielectric, $\mathrm{InO}_{x}$ TFTs were fabricated. Figure 3a-c show the transfer characteristics of $\mathrm{InO}_{x}$ TFTs fabricated with $\mathrm{AlO}_{x}$ gate dielectric layer annealed at different temperatures. In the case of the $150{ }^{\circ} \mathrm{C}$-annealed $\mathrm{AlO}_{x}$ gate dielectric, an average field-effect mobility of $183.0 \mathrm{~cm}^{2} / \mathrm{Vs}$ was observed, which is remarkably high as compared to those made with $\mathrm{SiO}_{2}$ gate dielectrics [23,24]. The exceptionally high mobility observed using the $\mathrm{AlO}_{x}$ gate dielectric can be attributed to the formation of an EDL due to a large amount of residual -OHs inside the $\mathrm{AlO}_{x}$ films [25]. In addition to the positive gate bias, a substantial number of electrons are accumulated near the $\mathrm{AlO}_{x} / \mathrm{InO}_{x}$ interface due to the EDL formation. These additional electrons contribute to the drain current resulting in a high drain current and increased field-effect mobility, as well as a large counter-clockwise hysteresis. As mentioned above, the formation of EDL is due to the mobile ions, including - $\mathrm{OH}$ residues in the $\mathrm{AlO}_{x}$ gate dielectric layer. As shown in Figure $3 \mathrm{~b}, \mathrm{c}$, the drain current and the field-effect mobility decreased as the annealing temperature increased. Particularly, with annealing temperatures of $250{ }^{\circ} \mathrm{C}$ and $350{ }^{\circ} \mathrm{C}$, the field-effect mobility was decreased to $45.5 \mathrm{~cm}^{2} / \mathrm{Vs}$ and $5.47 \mathrm{~cm}^{2} / \mathrm{Vs}$, respectively. At a higher annealing temperature, the number of mobile ions dramatically decreases, which drives the formation of a weak EDL and a low carrier concentration at the $\mathrm{AlO}_{x} / \mathrm{InO}_{x}$ interface.

In the case of the HGD gate dielectric layer, similar behavior was observed. Figure $4 a-c$ show the transfer characteristics of $\mathrm{InO}_{x}$ TFTs fabricated with the HGD gate dielectric layer annealed at different temperatures. The $\mathrm{InO}_{x}$ TFTs fabricated with a $150{ }^{\circ} \mathrm{C}$-annealed HGD gate dielectric showed an average field-effect mobility of $120.2 \mathrm{~cm}^{2} / \mathrm{Vs}$. Additionally, in the case of $250{ }^{\circ} \mathrm{C}$ - and $350{ }^{\circ} \mathrm{C}$-annealed HGD gate dielectrics, field-effect mobilities of $94.3 \mathrm{~cm}^{2} / \mathrm{Vs}$ and $16.1 \mathrm{~cm}^{2} /$ Vs were observed, respectively, showing a similar decreasing trend with the annealing temperature. This decreasing trend of mobility with annealing temperature can also be attributed to the decrease of the mobile ions and corresponding weak EDL formation. The relatively superior mobility in the HGD devices can be described by the aforementioned polymer network confinement of the mobile ions in the HGD [20]. Nonetheless, the solution-processed HGD gate dielectrics allow the acceptable formation of EDL at the gate dielectric/ $\mathrm{InO}_{x}$ interface, which significantly enhances the electrical properties of $\mathrm{InO}_{x}$ TFTs compared to the bare $\mathrm{AlO}_{x}$ films. In addition, due to the high dielectric constant and low thickness of the gate dielectric layers, low voltage operation below $6 \mathrm{~V}$ was possible, enabling low power consuming electronic devices. 
(a)

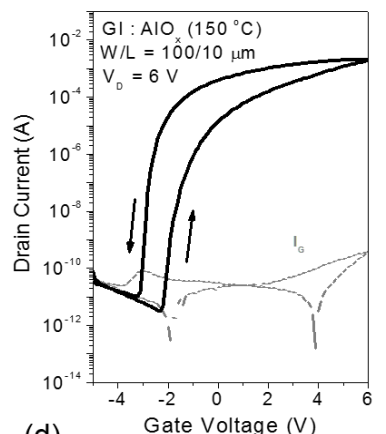

(d)

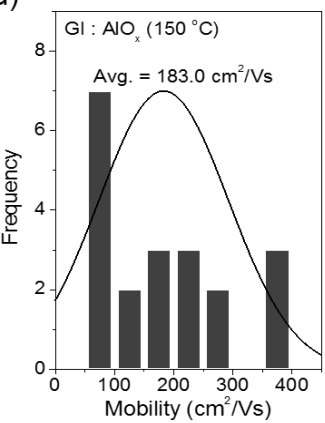

(b)

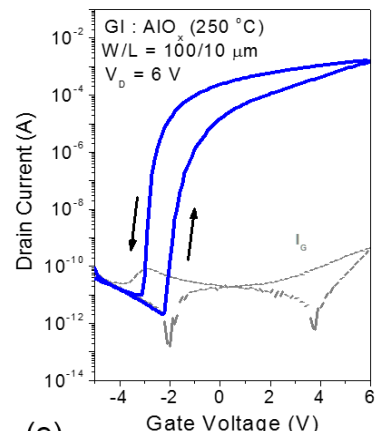

(e)

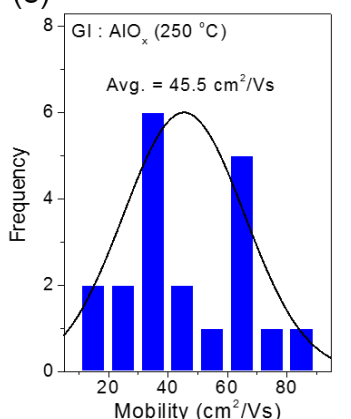

(c)

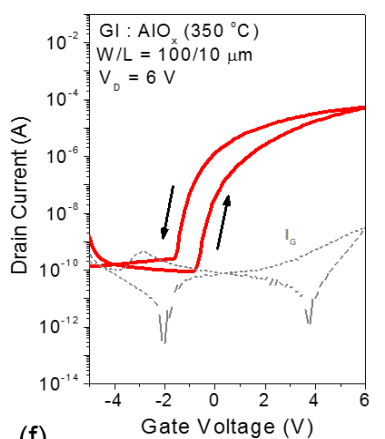

(f)

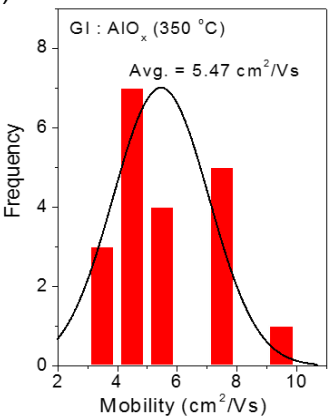

Figure 3. Electrical characteristics of various solution-processed $\mathrm{InO}_{x} \mathrm{TFTs}$ on an $\mathrm{AlO}_{x}$ dielectric layer for the different processed conditions. The transfer curves for $\mathrm{InO}_{x}$ TFTs with (a) $150{ }^{\circ} \mathrm{C}$-annealed; (b) $250{ }^{\circ} \mathrm{C}$-annealed; and (c) $350{ }^{\circ} \mathrm{C}$-annealed $\mathrm{AlO}_{x}$ films; the dotted lines indicate the gate leakage current. Statistical distribution of field-effect mobilities for $\mathrm{InO}_{x}$ TFTs with (d) $150{ }^{\circ} \mathrm{C}$-annealed; (e) $250{ }^{\circ} \mathrm{C}$-annealed; and (f) $350{ }^{\circ} \mathrm{C}$-annealed $\mathrm{AlO}_{x}$ films.

(a)

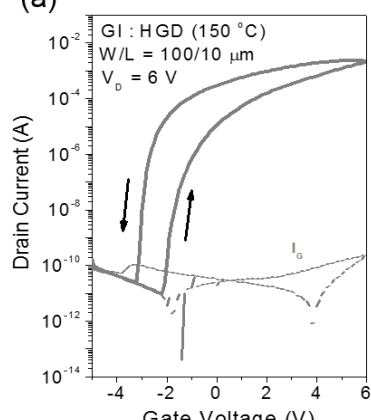

(d)

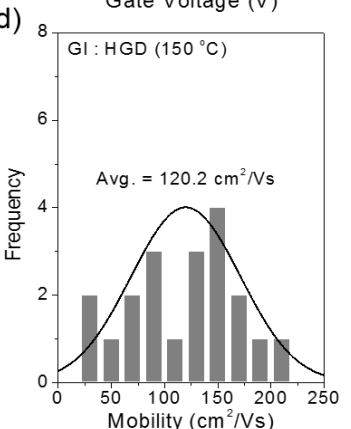

(b)

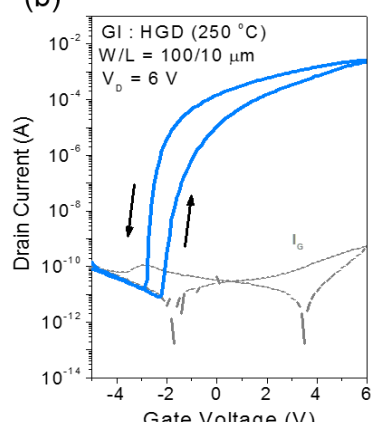

(e)

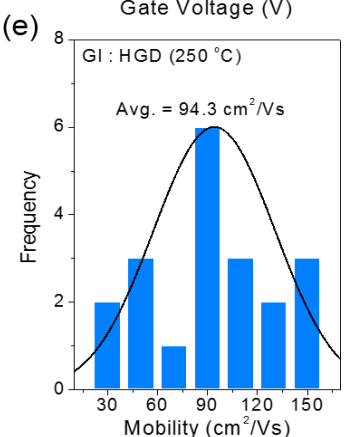

(c)

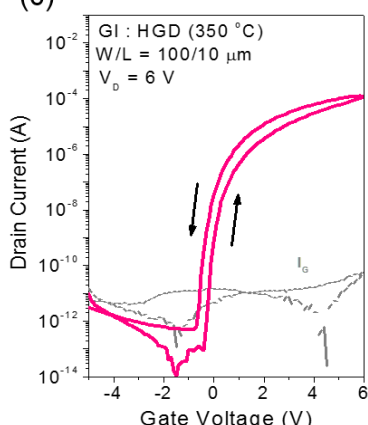

(f)

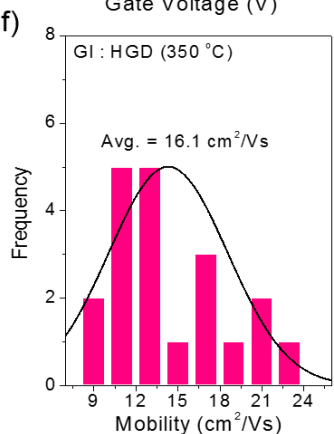

Figure 4. Electrical characteristics of various solution-processed $\mathrm{InO}_{x}$ TFTs on an HGD dielectric layer for the different processed conditions. The transfer curves for $\mathrm{InO}_{x}$ TFTs with (a) $150{ }^{\circ} \mathrm{C}$-annealed; (b) $250{ }^{\circ} \mathrm{C}$-annealed; and (c) $350^{\circ} \mathrm{C}$-annealed HGD films. The dotted lines indicate the gate leakage current. Statistical distribution of field-effect mobilities for $\mathrm{InO}_{x}$ TFTs with (d) $150{ }^{\circ} \mathrm{C}$-annealed; (e) $250{ }^{\circ} \mathrm{C}$-annealed; and (f) $350{ }^{\circ} \mathrm{C}$-annealed HGD films. 
In oxide semiconductor-based TFTs, the operational stabilities under positive gate bias stress (PBS) and negative illumination gate bias stress (NBIS) are important factors. In order to determine the operational stability of $\mathrm{InO}_{x}$ TFTs using the HGD gate dielectric, PBS and NBIS tests were carried out. Figure 5a shows the variation of transfer characteristics in $\mathrm{InO}_{x}$ TFTs under PBS. Here, the gate bias was set at $+3 \mathrm{~V}$, and the transfer curves were measured at 60, 360, and $3960 \mathrm{~s}$. As shown in Figure $5 b$, the device exhibited reasonably small threshold voltage shift $\left(\Delta \mathrm{V}_{\mathrm{T}}=-1.67 \mathrm{~V}\right)$ during the $3960 \mathrm{~s}$ of PBS. Typically, under PBS conditions, oxide TFTs tend to have positive $\mathrm{V}_{\mathrm{T}}$ shift due to the electron trapping at the gate dielectric/semiconductor interface [26-28]. However, in the case of $\mathrm{InO}_{x}$ TFTs using the HGD gate dielectric, a negative $V_{T}$ shift was observed. This opposite behavior in $V_{T}$ instability is possibly caused by the mobile ions present in the HGD gate dielectric. Particularly, under a continuous PBS condition, a significant amount of positively charged mobile ions move towards the $\mathrm{InO}_{x} / \mathrm{HGD}$ interface (Figure 6a). These positive mobile ions, then, contribute to the accumulation of electrons in the $\mathrm{InO}_{x}$ channel layer. However, due to the slow responsive characteristic of mobile ions [29-31], they tend to remain near the $\mathrm{InO}_{x} / \mathrm{HGD}$ interface causing a negative shift of transfer curves. In addition, the stability under the NBIS condition was also analyzed. Figure $5 c, d$ show the variation of transfer characteristics and $\mathrm{V}_{\mathrm{T}}$ under NBIS condition, respectively. Surprisingly, the $\mathrm{InO}_{x}$ TFT showed extremely high stability against NBIS and showed $\Delta \mathrm{V}_{\mathrm{T}}$ of $-0.23 \mathrm{~V}$ (after $3960 \mathrm{~s}$ ). Typically, the NBIS causes a significant negative $V_{T}$ shift due to the ionization of neutral oxygen vacancies and negative-bias-induced hole injection in the gate dielectric layer [32-35]. However, the $\mathrm{InO}_{x} \mathrm{TFT}$ with HGD gate dielectric showed negligible $\mathrm{V}_{\mathrm{T}}$ shift under a prolonged light illumination and negative bias condition. This significant reduction in the $\mathrm{V}_{\mathrm{T}}$ shift can be attributed to the neutralization of injected holes with the negatively charged mobile ions near the $\mathrm{InO}_{x} / \mathrm{HGD}$ interface (Figure 6b). As a consequence, the device can exhibit a high operational stability under NBIS. Furthermore, it should be noted that the $\mathrm{InO}_{x}$ TFTs with an HGD dielectric layer exhibited fast recovery after the PBS and NBIS tests. It was found that the $\mathrm{V}_{\mathrm{T}}$ was recovered to original states after around 6 min, which can be attributed to the gradual neutralization of EDL during the recovery.

(a)
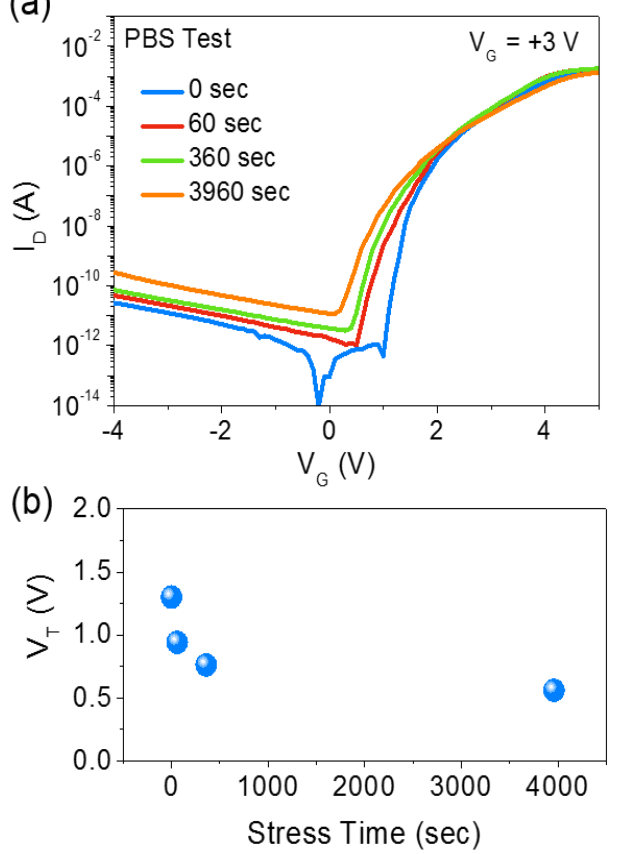

(c)

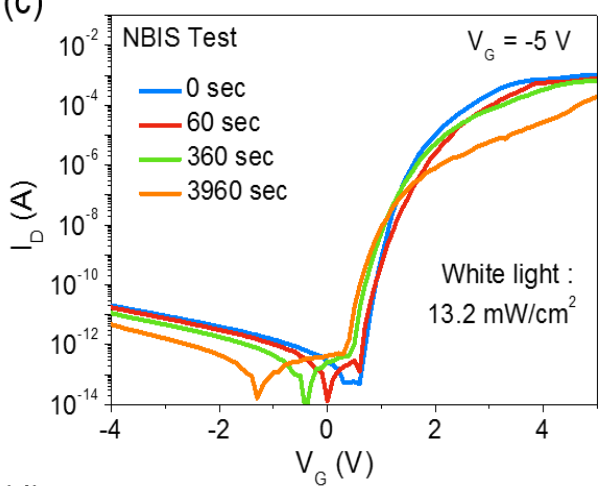

(d)

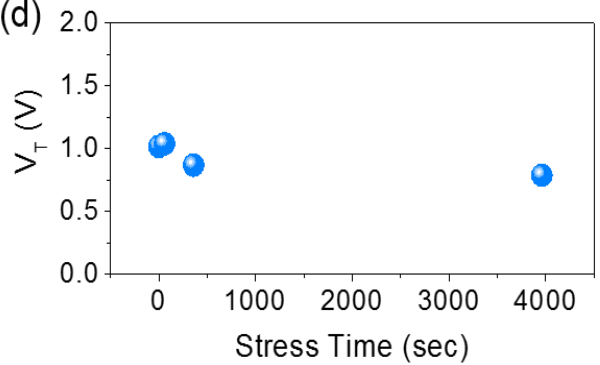

Figure 5. (a) Positive gate bias stability and (b) evolution of threshold voltage $\left(\mathrm{V}_{\mathrm{T}}\right)$ of solution-processed $\mathrm{InO}_{x}$ TFTs with the $150{ }^{\circ} \mathrm{C}$-annealed HGD dielectric layer $\left(\mathrm{V}_{\mathrm{GS}}=+3 \mathrm{~V}, \mathrm{t}=3960 \mathrm{~s}\right)$; (c) negative gate bias illumination stability and $(\mathbf{d})$ evolution of threshold voltage $\left(\mathrm{V}_{\mathrm{T}}\right)$ of solution-processed $\operatorname{InO}_{x}$ TFTs with the $150{ }^{\circ} \mathrm{C}$-annealed HGD dielectric layer $\left(\mathrm{V}_{\mathrm{GS}}=-5 \mathrm{~V}, \mathrm{t}=3960 \mathrm{~s}\right)$. 
(a)

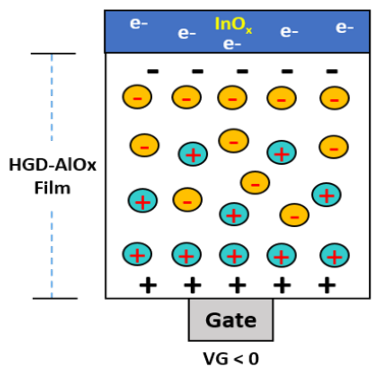

(b)
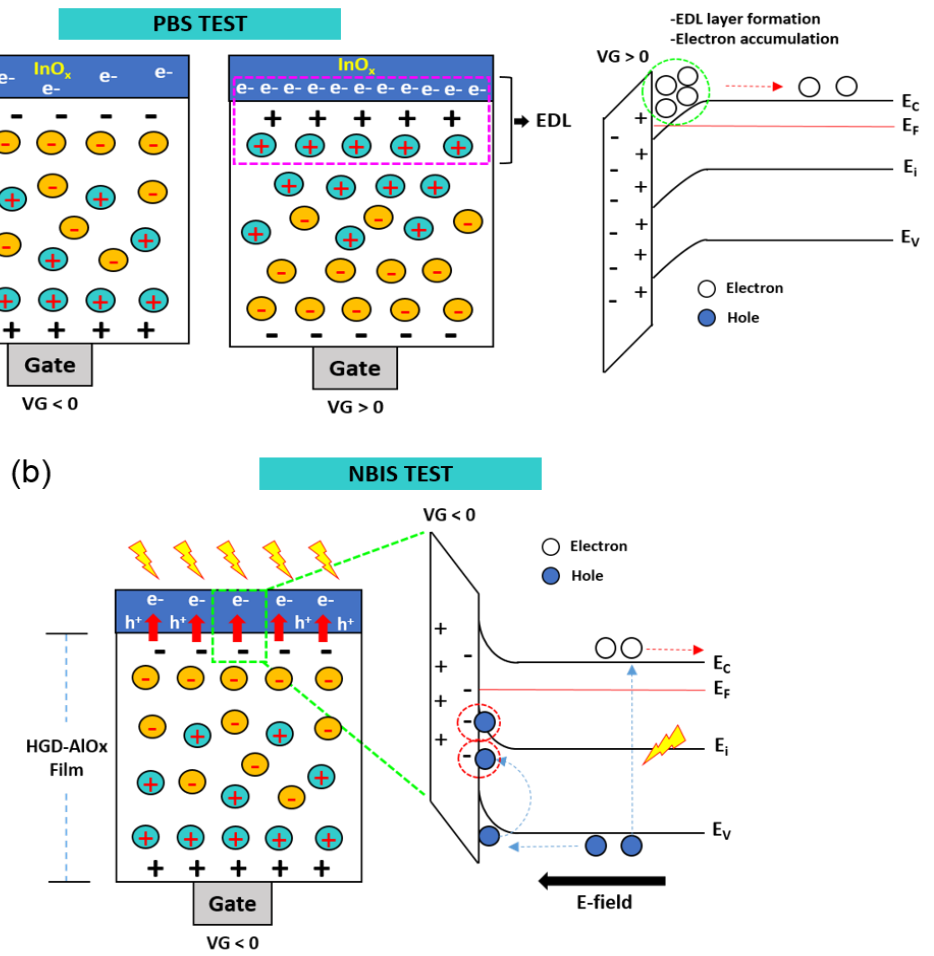

Figure 6. Schematic and energy band diagrams of corresponding $\mathrm{V}_{\mathrm{T}}$ instability of solution-processed $\mathrm{InO}_{x}$ TFT with the $150{ }^{\circ} \mathrm{C}$-annealed HGD dielectric layer for (a) PBS and (b) NBIS tests.

\section{Conclusions}

In this paper, we demonstrated high-mobility, operationally stable $\mathrm{InO}_{x}$ TFTs by using ionic-type $\mathrm{AlO}_{x}$ and HGD gate dielectrics. The solution-processed $\mathrm{AlO}_{x}$ and HGD exhibited reasonably high capacitance and dielectric constant, and only a small decrease in capacitance was observed at high frequencies, enabling a high frequency operation. Using the solution-processed HGD gate dielectrics with $350{ }^{\circ} \mathrm{C}$ annealing treatment, solution-processed $\mathrm{InO}_{x}$ TFTs were fabricated with an average field-effect mobility of $16.1 \mathrm{~cm}^{2} /$ Vs with minimal hysteresis. In addition, the HGD gate dielectric also suppressed the negative $\mathrm{V}_{\mathrm{T}}$ shift during the NBIS condition, which enhanced the operation stability of the $\mathrm{InO}_{x}$ TFTs.

Acknowledgments: This work was partially supported by the Human Resources Development (No. 20154030200860) of the Korea Institute of Energy Technology Evaluation and Planning (KETEP) grant funded by the Korea government Ministry of Trade, Industry and Energy and by the Chung-Ang University Research Scholarship Grants in 2016.

Author Contributions: Jae Sang Heo, Seungbeom Choi, Jeong-Wan Jo, and Jingu Kang performed the experiments and the data analysis. Sung Kyu Park, Yong-Hoon Kim, and Ho-Hyun Park helped draft the manuscript and carry out data analysis and evaluation. Sung Kyu Park and Yong-Hoon Kim made substantial contributions to the concept of experiments and were responsible for leading the project. All authors read and approve the final manuscript.

Conflicts of Interest: The authors declare no conflict of interest.

\section{References}

1. Nomura, K.; Ohta, H.; Ueda, K.; Kamiya, T.; Hirano, M.; Hosono, H. Thin-film transistor fabricated in single-crystalline transparent oxide semiconductor. Science 2003, 300, 1269-1272. [CrossRef] [PubMed]

2. Nomura, K.; Ohta, H.; Takagi, A.; Kamiya, T.; Hirano, M.; Hosono, H. Room-temperature fabrication of transparent flexible thin-film transistors using amorphous oxide semiconductors. Nature 2004, 432, 488-492. [CrossRef] [PubMed] 
3. Liu, J.; Buchholz, D.B.; Chang, R.P.H.; Facchetti, A.; Marks, T.J. High-performance flexible transparent thin-film transistors using a hybrid gate dielectric and an amorphous zinc indium tin oxide channel. Adv. Mater. 2010, 22, 2333-2337. [CrossRef] [PubMed]

4. Kim, Y.-H.; Heo, J.-S.; Kim, T.-H.; Park, S.; Yoon, M.-H.; Kim, J.; Oh, M.S.; Yi, G.-R.; Noh, Y.-Y.; Park, S.K. Flexible metal-oxide devices made by room-temperature photochemical activation of sol-gel films. Nature 2012, 489, 128-132. [CrossRef] [PubMed]

5. Lee, S.; Shin, J.; Jang, J. Top Interface Engineering of Flexible Oxide Thin-Film Transistors by Splitting Active Layer. Adv. Funct. Mater. 2017, 27, 1604921. [CrossRef]

6. Rembert, T.; Battaglia, C.; Anders, A.; Javey, A. Room Temperature Oxide Deposition Approach to Fully Transparent, All-Oxide Thin-Film Transistors. Adv. Mater. 2015, 27, 6090-6095. [CrossRef] [PubMed]

7. Banger, K.K.; Yamashita, Y.; Mori, K.; Peterson, R.L.; Leedham, T.; Rickard, J.; Sirringhaus, H. Low-temperature, high-performance solution-processed metal oxide thin-film transistors formed by a "sol-gel on chip" process. Nat. Mater. 2011, 10, 45-50. [CrossRef] [PubMed]

8. Chang, J.; Chang, K.L.; Chi, C.; Zhang, J.; Wu, J. Water induced zinc oxide thin film formation and its transistor performance. J. Mater. Chem. C 2014, 2, 5397. [CrossRef]

9. Pal, B.N.; Dhar, B.M.; See, K.C.; Katz, H.E. Solution-deposited sodium beta-alumina gate dielectrics for low-voltage and transparent field-effect transistors. Nat. Mater. 2009, 8, 898-903. [CrossRef] [PubMed]

10. Jo, J.-W.; Kim, J.; Kim, K.-T.; Kang, J.-G.; Kim, M.-G.; Kim, K.-H.; Ko, H.; Kim, Y.-H.; Park, S.K. Highly Stable and Imperceptible Electronics Utilizing Photoactivated Heterogeneous Sol-Gel Metal-Oxide Dielectrics and Semiconductors. Adv. Mater. 2015, 27, 1182-1188. [CrossRef] [PubMed]

11. Lin, Y.-H.; Faber, H.; Labram, J.G.; Stratakis, E.; Sygellou, L.; Kymakis, E.; Hastas, N.A.; Li, R.; Zhao, K.; Amassian, A.; et al. High Electron Mobility Thin-Film Transistors Based on Solution-Processed Semiconducting Metal Oxide Heterojunctions and Quasi-Superlattices. Adv. Sci. 2015, 2, 1500058. [CrossRef] [PubMed]

12. Ahn, C.H.; Cho, H.K.; Kim, H. Carrier confinement effect-driven channel design and achievement of robust electrical/photostability and high mobility in oxide thin-film transistors. J. Mater. Chem. C 2016, 4, 727-735. [CrossRef]

13. Kim, M.-G.; Kanatzidis, M.G.; Facchetti, A.; Marks, T.J. Low-temperature fabrication of high-performance metal oxide thin-film electronics via combustion processing. Nat. Mater. 2011, 10, 382-388. [CrossRef] [PubMed]

14. Heo, J.S.; Jo, J.W.; Kang, J.; Jeong, C.Y.; Jeong, H.Y.; Kim, S.K.; Kim, K.; Kwon, H.I.; Kim, J.; Kim, Y.H.; et al. Water-Mediated Photochemical Treatments for Low-Temperature Passivation of Metal-Oxide Thin-Film Transistors. ACS Appl. Mater. Interfaces 2016, 8, 10403-10412. [CrossRef] [PubMed]

15. Fujii, M.N.; Ishikawa, Y.; Miwa, K.; Okada, H.; Uraoka, Y.; Ono, S. High-density carrier-accumulated and electrically stable oxide thin-film transistors from ion-gel gate dielectric. Sci. Rep. 2015, 5, 18168. [CrossRef] [PubMed]

16. Cho, J.H.; Lee, J.; He, Y.; Kim, B.; Lodge, T.P.; Frisbie, C.D. High-capacitance ion gel gate dielectrics with faster polarization response times for organic thin film transistors. Adv. Mater. 2008, 20, 686-690. [CrossRef]

17. Tölle, F.J.; Fabritius, M.; Mülhaupt, R. Aerosol Jet Printed p- and n-type Electrolyte-Gated Transistors with a Variety of Electrode Materials Exploring Practical Routes to Printed Electronics. Adv. Funct. Mater. 2012, 22, 1136-1144. [CrossRef]

18. Pudasaini, P.R.; Noh, J.H.; Wong, A.T.; Ovchinnikova, O.S.; Haglund, A.V.; Dai, S.; Ward, T.Z.; Mandrus, D.; Rack, P.D. Ionic Liquid Activation of Amorphous Metal-Oxide Semiconductors for Flexible Transparent Electronic Devices. Adv. Funct. Mater. 2016, 26, 2820-2825. [CrossRef]

19. Pudasaini, P.R.; Noh, J.H.; Wong, A.; Haglund, A.V.; Dai, S.; Ward, T.Z.; Mandrus, D.; Rack, P.D. Ionic Liquid versus $\mathrm{SiO}_{2}$ Gated a-IGZO Thin Film Transistors: A Direct Comparison. ECS J. Solid State Sci. Technol. 2015, 4, Q105-Q109. [CrossRef]

20. Cho, J.H.; Lee, J.; Xia, Y.; Kim, B.; He, Y.; Renn, M.J.; Lodge, T.P.; Daniel Frisbie, C. Printable ion-gel gate dielectrics for low-voltage polymer thin-film transistors on plastic. Nat. Mater. 2008, 7, 900-906. [CrossRef] [PubMed]

21. Ma, H.; Wang, Y.; Wu, D.; Zhang, Y.; Gao, J.; Ren, X.; Du, B.; Wei, Q. A Novel Controlled Release Immunosensor based on Benzimidazole Functionalized $\mathrm{SiO}_{2}$ and $\mathrm{Cyclodextrin}$ Functionalized Gold. Sci. Rep. 2016, 6, 19797. [CrossRef] [PubMed] 
22. Park, H.; Nam, Y.; Jin, J.; Bae, B.-S. Space charge-induced unusually-high mobility of a solution-processed indium oxide thin film transistor with an ethylene glycol incorporated aluminum oxide gate dielectric. RSC Adv. 2015, 5, 102362-102366. [CrossRef]

23. Kim, M.G.; Kim, H.S.; Ha, Y.G.; He, J.; Kanatzidis, M.G.; Facchetti, A.; Marks, T.J. High-performance solution-processed amorphous zinc-indium-tin oxide thin-film transistors. J. Am. Chem. Soc. 2010, 132, 10352-10364. [CrossRef] [PubMed]

24. Rim, Y.S.; Chen, H.; Kou, X.; Duan, H.S.; Zhou, H.; Cai, M.; Kim, H.J.; Yang, Y. Boost up mobility of solution-processed metal oxide thin-film transistors via confining structure on electron pathways. Adv. Mater. 2014, 26, 4273-4278. [CrossRef] [PubMed]

25. Banger, K.; Warwick, C.; Lang, J.; Broch, K.; Halpert, J.E.; Socratous, J.; Brown, A.; Leedham, T.; Sirringhaus, H. Identification of dipole disorder in low temperature solution processed oxides: Its utility and suppression for transparent high performance solution-processed hybrid electronics. Chem. Sci. 2016, 10, 45-50. [CrossRef] [PubMed]

26. Kimura, M.; Nakanishi, T.; Nomura, K.; Kamiya, T.; Hosono, H. Trap densities in amorphous-InGaZnO 4 thin-film transistors. Appl. Phys. Lett. 2008, 92, 13-16. [CrossRef]

27. Seo, J.-S.; Bae, B.-S. Improved Electrical Performance and Bias Stability of Solution-Processed Active Bilayer Structure of Indium Zinc Oxide based TFT. ACS Appl. Mater. Interfaces 2014, 6, 15335-15343. [CrossRef] [PubMed]

28. Chen, W.T.; Lo, S.Y.; Kao, S.C.; Zan, H.W.; Tsai, C.C.; Lin, J.H.; Fang, C.H.; Lee, C.C. Oxygen-dependent instability and annealing/passivation effects in amorphous In-Ga-Zn-O thin-film transistors. IEEE Electron Device Lett. 2011, 32, 1552-1554. [CrossRef]

29. Narasimhan, V.; Park, S.Y. An Ion Gel as a Low-Cost, Spin-Coatable, High-Capacitance Dielectric for Electrowetting-on-Dielectric (EWOD). Langmuir 2015, 31, 8512-8518. [CrossRef] [PubMed]

30. Larsson, O.; Said, E.; Berggren, M.; Crispin, X. Insulator polarization mechanisms in polyelectrolyte-gated organic field-effect transistors. Adv. Funct. Mater. 2009, 19, 3334-3341. [CrossRef]

31. Nketia-Yawson, B.; Kang, S.-J.; Tabi, G.D.; Perinot, A.; Caironi, M.; Facchetti, A.; Noh, Y.-Y. Ultrahigh Mobility in Solution-Processed Solid-State Electrolyte-Gated Transistors. Adv. Mater. 2017, 29, 1605685. [CrossRef] [PubMed]

32. Chowdhury, M.D.H.; Migliorato, P.; Jang, J. Light induced instabilities in amorphous indium-galliumzinc-oxide thin-film transistors. Appl. Phys. Lett. 2010, 97, 10-13. [CrossRef]

33. Rim, Y.S.; Jeong, W.; Ahn, B.D.; Kim, H.J. Defect reduction in photon-accelerated negative bias instability of InGaZnO thin-film transistors by high-pressure water vapor annealing. Appl. Phys. Lett. 2013, 102, 143503.

34. Jo, J.-W.; Kim, Y.-H.; Park, S.K. Light-induced hysteresis and recovery behaviors in photochemically activated solution-processed metal-oxide thin-film transistors. Appl. Phys. Lett. 2014, 105, 43503. [CrossRef]

35. Ueoka, Y.; Ishikawa, Y.; Bermundo, J.P.; Yamazaki, H.; Urakawa, S.; Fujii, M.; Horita, M.; Uraoka, Y. Density of States in Amorphous In-Ga-Zn-O Thin-Film Transistor under Negative Bias Illumination Stress. ECS J. Solid State Sci. Technol. 2014, 3, Q3001-Q3004. [CrossRef]

(C) 2017 by the authors. Licensee MDPI, Basel, Switzerland. This article is an open access article distributed under the terms and conditions of the Creative Commons Attribution (CC BY) license (http://creativecommons.org/licenses/by/4.0/). 